\title{
Theoretical investigation on orange-emitting cyclometalated platinum (II) complexes containing organosilyl/ organocarbon-substituted 2-(2-thienyl)pyridine ligands
}

\author{
Hadj Mezouar ${ }^{1,2} \cdot$ Houari Brahim ${ }^{1}$
}

Received: 11 December 2021 / Accepted: 17 February 2022 / Published online: 5 March 2022

(c) The Author(s), under exclusive licence to European Photochemistry Association, European Society for Photobiology 2022

\begin{abstract}
This paper presents a theoretical investigation of structural, optical, and phosphorescence properties of four cyclometalated Pt(II) complexes containing substituted 2-(2-thienyl)pyridine ligands using DFT and TD-DFT methods. Geometrical parameters of ground states were calculated and compared with available experimental data. Electronic absorptions were studied and assigned in terms of natural transition orbitals. Phosphorescence spectra have been simulated with adiabatic Hessian and adiabatic shift approaches according to the Franck-Condon approximation. Theoretical and experimental results agree and show that the four complexes exhibit two intense bands in orange region. Main normal modes involved in phosphorescence bands were analyzed and assigned.
\end{abstract}

\section{Graphical abstract}

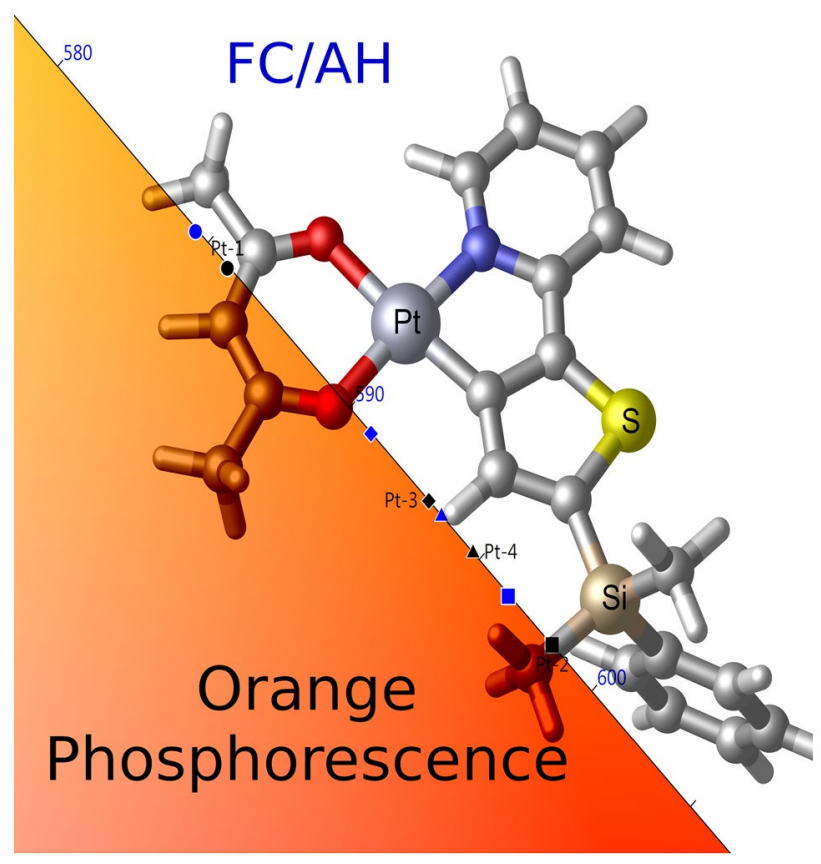

Keywords TD-DFT $\cdot$ Platinum $\cdot$ Complexes $\cdot$ Absorption $\cdot$ Phosphorescence $\cdot$ Organosilyl $\cdot$ Organocarbon

Houari Brahim

brahim.h@outlook.com

Extended author information available on the last page of the article 


\section{Introduction}

Cyclometalated platinum (II) complexes have been extensively studied in the past two decades for use in different domain and application e.g. photoredox catalytic reaction, bioimaging, sensors and as emitters for organic light emitting diodes (OLEDs) [1-9]. Platinum (II) and iridium (III) complexes containing 2-phenylpyridyl (ppy) have been widely investigated due to their high luminescence efficiencies and stability [10,11]. To improve luminescence quantum yield of theses complexes, scientists have focused their studies on replacing phenyl and/or pyridine of ppy by another aromatic group (such as thiophene, picolinate, and Schiff base) [12-15] or by introducing electron donating and/or withdrawing groups at different site in ppy ligand [16-18]. Also, combination of $\mathrm{C}^{\wedge} \mathrm{N}$ type ligands with acac ligand has also been considered to modify the optical properties of platinum complexes, notably the character of the lowest excited states to obtain better luminescence efficiency and tunable emission color [19-21]. Moreover, symmetry around metal ion plays an important role to enhancing the performance phosphorescent properties of platinum complexes [22-24].

Usuki and all have synthesized and characterized four cyclometalated Pt(II) complexes (thpy)Pt(acac) (Pt-1), (R-thpy)Pt(acac) (Pt-2), (R'-thpy)Pt(acac) (Pt-3) and $\left(\mathrm{R}^{\prime \prime}\right.$-(thpy)Pt(acac) $(\mathbf{P t}-4)$, with thpy $=(2-(2-$ thienyl)pyridine $),$ acac $=$ acetylacetonate, $R=(2$-phenylpropan-2-yl), $\mathrm{R}^{\prime}=$ (dimethyl(phenyl) silyl and $\mathrm{R}^{\prime \prime}=((2,6$-dimethylphenyl)(2-methoxyphenyl)(methyl)silyl) [25]. The structures of the four complexes were determined by X-ray diffraction analysis. Electronic absorption spectra, emission spectra and phosphorescence quantum yield were investigated. The authors studied effects of the introduction of a sidechain containing tetrahedral silicon or carbon fragments ( $R, \mathrm{R}^{\prime}$ and $\mathrm{R}^{\prime \prime}$ ) to thpy ligand on the phosphorescence properties of (thpy)Pt(acac) complex in solution and in the solid state. They reveal that all complexes exhibited orange emission bands between 500 and $800 \mathrm{~nm}$ with high phosphorescence efficiency. In this work, we studied the structural, optical and phosphorescence properties of Pt-1, Pt-2, Pt-3 and Pt-4 complexes by mean density functional theory (DFT) and its time-dependent extension (TD-DFT) methods. Our study provides detailed information on structural and electronic properties of the ground state $\left(\mathrm{S}_{0}\right)$ and the first excited triplet state $\left(T_{1}\right)$ of the four complexes. The phosphorescence spectra were studied taking into account the vibronic contributions to $\mathrm{T}_{1}-\mathrm{S}_{0}$ transition. The vibrational modes responsible for the phosphorescence signatures were identified and assigned.

\section{Computational details}

Starting from X-ray geometries, the four complexes Pt-1, Pt-2, Pt-3 and Pt-4 were optimized in chloroform using hybrid exchange-correlation functional B3PW91 [26-29]. LANL2DZ [30, 31] base set was employed for all atoms, augmented with $d$ polarization functions on $\mathrm{C}(0.587)$, $\mathrm{N}(0.736), \mathrm{S}(0.496)$, and $\mathrm{O}(0.961)$, and augmented with $f$ polarization functions on $\operatorname{Pt}(0.993)$. The "relativistic" HayWat pseudo-potential was used to describe the inner electron of the Pt, Si and $\mathrm{S}$. The choice of this calculation level is justified by the good results obtained in previous work for similar complexes [32-34]. The solvent effects were introduced using the polarizable continuum model (PCM) [35, 36]. Electronic absorption spectra were studied using TD-B3PW91 method with same basis sets used above. All spectra were simulated with Gaussian function $(\mathrm{FWHM}=0.35 \mathrm{eV})$ using Gabedit program [37]. The first triplet excited states $T_{1}$ of the studied complexes were optimized using unrestricted DFT (UB3PW91/LANL2DZ) in chloroform. Frequency calculations were performed to confirm that both $\mathrm{S}_{0}$ and $\mathrm{T}_{1}$ of all complexes correspond to true minima on the Potential Energy Surface (PES). Phosphorescence wavelengths were computed with $\Delta \mathrm{SCF}^{\mathrm{vert}}$ and $\Delta \mathrm{SCF}^{\text {adiab }}$ procedures. To simulate the emission spectra, the vibrational contributions to the $\mathrm{T}_{1}-\mathrm{S}_{0}$ transition were studied using adiabatic Hessian ( $\mathrm{AH})$ and adiabatic shift (AS) approaches according to the Franck-Condon (FC) approximation. Emission spectra were plotted using VMS program [38]. All calculations were performed by Gaussian 09 [39]. We have use Avogadro-1 [37] to get isosurface orbitals and to visualizing geometric structures.

\section{Results and discussion}

\subsection{Geometric structures and frontier molecular orbitals}

Starting from X-ray structures, the geometries of the studied complexes Pt-1, Pt-2, Pt-3 and Pt-4 (Fig. 1) were fully optimized in chloroform using B3PW91 functional. Selected bond lengths and angles are given in Table 1 together with experimental values. Around the metal, computed and recorded results agree except for Pt- $\mathrm{O}_{2}$ bond lengths, the error is about $0.01 \AA$. For all studied complexes, $\mathrm{O}_{1}, \mathrm{O}_{2}, \mathrm{~N}$ and $\mathrm{C}_{1}$ adopt near-square planar arrangement around the platinum, almost coplanar with acac and thpy plans. In all complexes, $\mathrm{Pt}-\mathrm{O}_{1}$ bonds in cis position with pyridine are longer than $\mathrm{Pt}-\mathrm{O}_{2}$ bonds in cis position with thiophene group. For the sidechain, 


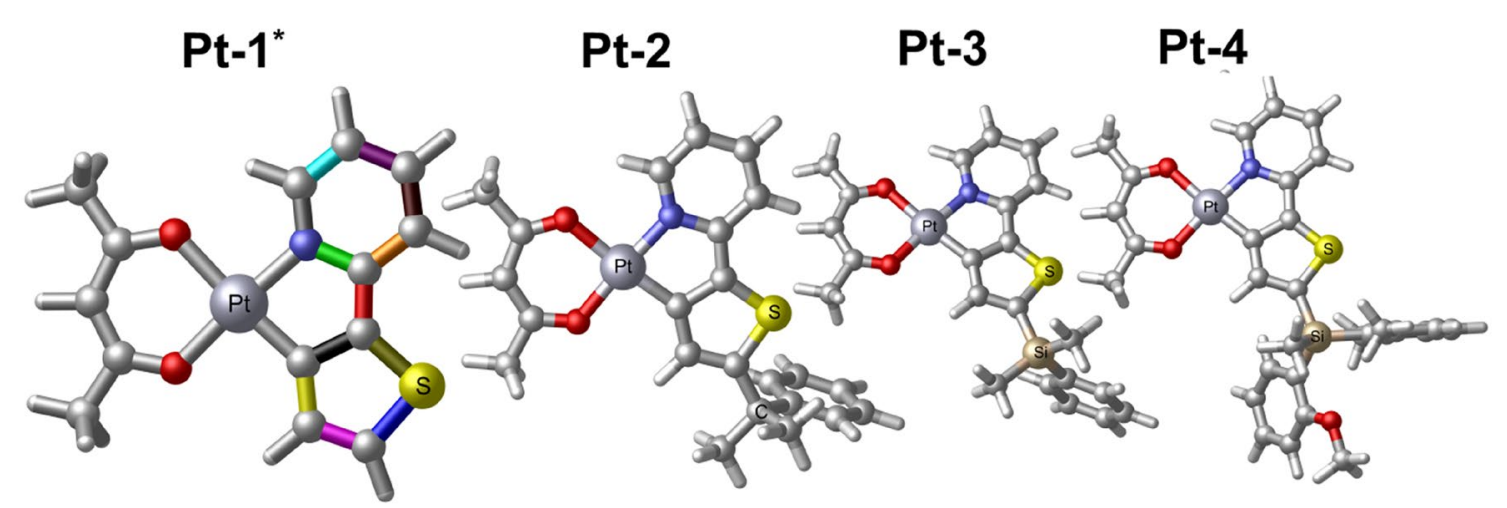

Fig. 1 Geometric structures of the four studied complexes obtained with B3PW91. *Colored bonds used in Table 4

Table 1 Selected optimized and experimental bond lengths (in $\AA$ ) and bond angles (in ${ }^{\circ}$ ) of the studied complexes calculated with B3PW91

\begin{tabular}{|c|c|c|c|c|c|c|c|}
\hline & \multirow{2}{*}{$\begin{array}{l}\text { Pt-1 } \\
\text { B3PW91 }\end{array}$} & \multicolumn{2}{|l|}{ Pt-2 } & \multicolumn{2}{|l|}{ Pt-3 } & \multicolumn{2}{|l|}{ Pt-4 } \\
\hline & & B3PW91 & Exp & B3PW91 & Exp & B3PW91 & Exp \\
\hline $\mathrm{Pt}-\mathrm{O}_{1}$ & 2.102 & 2.104 & 2.088 & 2.102 & 2.081 & 2.108 & 2.079 \\
\hline $\mathrm{Pt}-\mathrm{O}_{2}$ & 2.008 & 2.012 & 2.004 & 2.011 & 2.000 & 2.011 & 1.987 \\
\hline $\mathrm{Pt}-\mathrm{N}_{5}$ & 2.004 & 2.007 & 2.005 & 2.007 & 2.003 & 2.007 & 2.008 \\
\hline $\mathrm{Pt}-\mathrm{C}_{1}$ & 1.954 & 1.958 & 1.974 & 1.959 & 1.957 & 1.958 & 1.986 \\
\hline \multirow{3}{*}{$\begin{array}{l}(\mathrm{C}-\mathrm{C})^{\mathrm{a}} \\
(\mathrm{Si}-\mathrm{C})^{\mathrm{b}}\end{array}$} & & 1.523 & 1.539 & 1.879 & 1.853 & 1.886 & 1.873 \\
\hline & & 1.541 & 1.540 & 1.879 & 1.870 & 1.884 & 1.884 \\
\hline & & 1.538 & 1.540 & 1.888 & 1.881 & 1.894 & 1.888 \\
\hline $\mathrm{O}_{1}-\mathrm{Pt}-\mathrm{O}_{2}$ & 91.5 & 91.5 & 93.4 & 91.5 & 92.9 & 91.9 & 93.1 \\
\hline $\mathrm{O}_{1}-\mathrm{Pt}-\mathrm{N}$ & 93.2 & 93.2 & 92.3 & 93.4 & 92.9 & 93.5 & 91.0 \\
\hline $\mathrm{C}_{1}-\mathrm{Pt}-\mathrm{O}_{2}$ & 93.8 & 93.9 & 91.9 & 93.7 & 92.8 & 93.6 & 94.1 \\
\hline $\mathrm{C}_{1}-\mathrm{Pt}-\mathrm{N}$ & 81.3 & 81.2 & 81.1 & 81.2 & 81.2 & 81.3 & 81.5 \\
\hline $\mathrm{C}_{1}-\mathrm{Pt}-\mathrm{O}_{1}$ & 174.6 & 174.5 & 173.6 & 174.7 & 173.3 & 174.8 & 172.4 \\
\hline $\mathrm{O}_{2}-\mathrm{Pt}-\mathrm{N}$ & 175.1 & 175.1 & 174.1 & 174.9 & 174.0 & 174.9 & 175.5 \\
\hline
\end{tabular}

${ }^{a}$ Bond lengths around the tetrahedral carbon $(\mathrm{C})$ of sidechain in Pt-2

${ }^{\mathrm{b}}$ Bond lengths around the tetrahedral silicon ( $\mathrm{Si}$ ) of sidechain in Pt-3 and Pt-4 bond lengths around the tetrahedral carbon (C) in Pt-2 are shorter $(\sim 1.5 \AA)$ than equivalent bond lengths around tetrahedral silicon $(\mathrm{Si})$ in Pt-3 and Pt-4 $(\sim 1.8 \AA)$, this result agree with experimental values.

Energy gaps and energy levels of selected frontier molecular orbitals (FMOs) and their composition are represented in Scheme 1. As Pt is bonded to four atoms in square planar symmetry, the highest occupied orbitals HOMO, H-1 and H-2 are contributed by a set of dPt orbitals, probably $\mathrm{d}_{\mathrm{yz}}, \mathrm{d}_{\mathrm{xy}}$ and $\mathrm{d}_{\mathrm{zz}}$. HOMOs of the studied complexes are composed with a mixed contribution of $\mathrm{dPt}$ and $\pi_{\text {thpy }}$ orbitales, with domination of thiophene moiety orbitals. $\mathrm{H}-1$ orbitals of the four complexes are delocalized over $\pi_{\mathrm{acac}}$ and dPt orbitals. H-2 orbitals of the four complexes, computed at $\sim-6.4 \mathrm{eV}$ are entirely localized in $\mathrm{d}_{\mathrm{z}}^{2}$ orbital of Pt. For the lowest unoccupied orbitals, LUMOs of all complexes are delocalized on $\pi_{\text {thpy }}^{\star}$ orbitals while $L+1$ of all complexes are delocalized principally on acetate and thiophene moiety. Noting that the sidechain do not contribute on the FMOs of Pt-2, Pt-3 and Pt-4 cited above. The first highest occupied orbitals containing a sidechain contribution have been calculated at $-6.90 \mathrm{eV}$ (Pt-2), $-7.03 \mathrm{eV}(\mathbf{P t}-3)$ and $-6.52 \mathrm{eV}(\mathbf{P t}-4)$. The introduction of the sidechain reduces slightly the energy gap in Pt-2, Pt-3 and Pt-4 compared to Pt-1. Energy gaps of Pt-3 and Pt-4 complexes containing tetrahedral silicon sidechain are equal $(3.653 \mathrm{eV})$ and $0.036 \mathrm{eV}$ larger than tetrahedral carbon sidechain (Scheme 1). 
Scheme 1 Energy gaps, FMO energy levels $(\mathrm{eV})$ and their composition of the studied complexes obtained with B3PW91

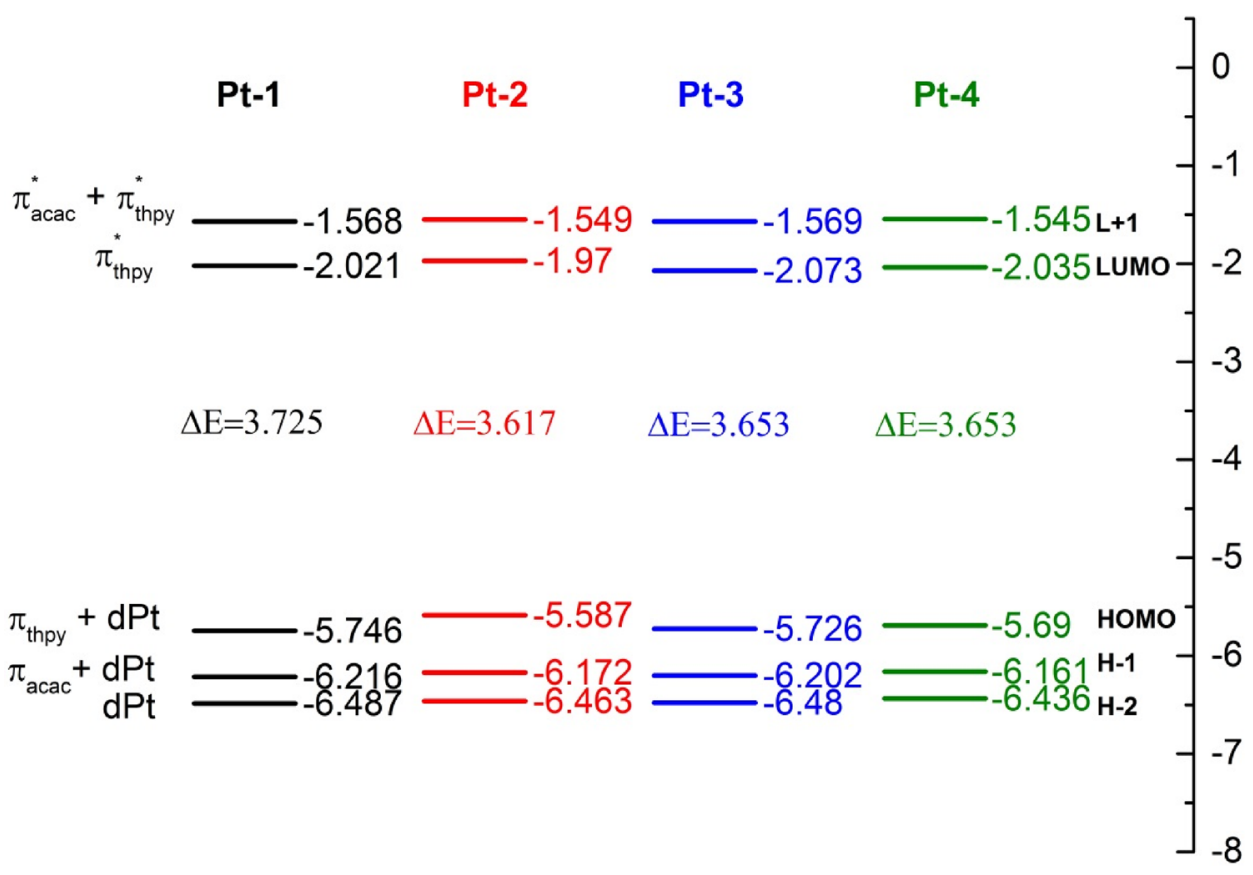

Table 2 Wavelengths $\left(\lambda_{\text {cal }}\right.$ and $\left.\lambda_{\text {exp }}\right)$, oscillator strengths and the character of selected singlet excited states. $\lambda_{\exp }$ from Ref [25]

\begin{tabular}{|c|c|c|c|c|c|}
\hline & $\lambda_{\text {cal }}$ & $f$ & Transition & Character & $\lambda_{\exp }$ \\
\hline \multicolumn{6}{|l|}{ Pt-1 } \\
\hline$S_{1}$ & 408 & 0.08 & $\mathrm{HOMO} \rightarrow \mathrm{LUMO}(93 \%)$ & LLCT/MLCT & 424 \\
\hline$S_{2}$ & 344 & 0.23 & $\begin{array}{l}\mathrm{H}-1 \rightarrow \mathrm{LUMO}(52 \%) \\
\mathrm{HOMO} \rightarrow \mathrm{L}+1(40 \%)\end{array}$ & LLCT/MLCT & \\
\hline $\mathrm{S}_{3}$ & 307 & 0.12 & $\begin{array}{l}\mathrm{H}-3 \rightarrow \text { LUMO }(62 \%) \\
\mathrm{H}-1 \rightarrow \mathrm{L}+1(18 \%)\end{array}$ & LLCT/MLCT & 316 \\
\hline \multicolumn{6}{|l|}{ Pt-2 } \\
\hline $\mathrm{S}_{1}$ & 419 & 0.10 & $\mathrm{HOMO} \rightarrow \mathrm{LUMO}(94 \%)$ & LLCT/MLCT & 434 \\
\hline $\mathrm{S}_{2}$ & 346 & 0.18 & $\begin{array}{l}\mathrm{H}-1 \rightarrow \mathrm{LUMO}(67 \%) \\
\mathrm{HOMO} \rightarrow \mathrm{L}+2(19 \%)\end{array}$ & LLCT/MLCT & \\
\hline $\mathrm{S}_{3}$ & 321 & 0.18 & $\begin{array}{l}\mathrm{H}-3 \rightarrow \mathrm{LUMO}(63 \%) \\
\mathrm{H}-1 \rightarrow \mathrm{L}+1(22 \%)\end{array}$ & LLCT/MLCT & 326 \\
\hline \multicolumn{6}{|l|}{ Pt-3 } \\
\hline $\mathrm{S}_{1}$ & 415 & 0.10 & $\mathrm{HOMO} \rightarrow \mathrm{LUMO}(93 \%)$ & LLCT/MLCT & 433 \\
\hline $\mathrm{S}_{2}$ & 348 & 0.21 & $\begin{array}{l}\mathrm{H}-1 \rightarrow \mathrm{LUMO}(38 \%) \\
\mathrm{HOMO} \rightarrow \mathrm{L}+1(57 \%)\end{array}$ & LLCT/MLCT & \\
\hline $\mathrm{S}_{3}$ & 315 & 0.23 & $\begin{array}{l}\mathrm{H}-3 \rightarrow \mathrm{LUMO}(59 \%) \\
\mathrm{H}-1 \rightarrow \mathrm{L}+1(24 \%)\end{array}$ & LLCT/MLCT & 319 \\
\hline \multicolumn{6}{|l|}{ Pt-4 } \\
\hline $\mathrm{S}_{1}$ & 415 & 0.11 & $\mathrm{HOMO} \rightarrow \mathrm{LUMO}(93 \%)$ & LLCT/MLCT & 429 \\
\hline $\mathrm{S}_{2}$ & 348 & 0.22 & $\begin{array}{l}\mathrm{H}-1 \rightarrow \text { LUMO }(43 \%) \\
\mathrm{HOMO} \rightarrow \mathrm{L}+1(51 \%)\end{array}$ & LLCT/MLCT & \\
\hline $\mathrm{S}_{3}$ & 317 & 0.27 & $\begin{array}{l}\mathrm{H}-4 \rightarrow \mathrm{LUMO}(62 \%) \\
\mathrm{H}-1 \rightarrow \mathrm{L}+1(18 \%)\end{array}$ & LLCT/MLCT & 319 \\
\hline
\end{tabular}

\subsection{Electronic absorption spectra}

On optimized geometries, low-lying singlet excited states of the four complexes have been studied in the chloroform using B3PW91 functional. Wavelengths, oscillator strengths, assignment and characters of main excited states are given in Table 2 together with experimental values. Simulated absorption spectra of the studied complexes are similar to experimental ones in both visible and UV regions (Fig. 2). $S_{0}-S_{n}$ absorptions were analyzed in term of NTOs (Pt-1, Pt-2 in Table S1 and Pt-3, Pt-4 in Table 3). In the visible region, $(\lambda>400 \mathrm{~nm})$ the absorption spectra of the four complexes exhibit a weak band attributed to $\mathrm{S}_{0}-\mathrm{S}_{1}$ absorptions, calculated at $408 \mathrm{~nm}(\mathbf{P t}-1), 419 \mathrm{~nm}$ (Pt-2), 415 nm (Pt-3) and 415 nm (Pt-4). NTO analyzes show that these absorptions have a mixed character ligand to ligand charge transfer (LLCT) and metal to ligand charge transfer (MLCT) which correspond principally to $\mathrm{dPt}+\pi_{\text {thiophene }} \rightarrow \pi_{\text {pyridine }}^{\star}$ transition. $S_{0}-S_{1}$ absorptions are assigned to the weak bands observed experimentally in visible domain of all complex spectra. Two intense absorptions $S_{0}-S_{2}$ and $S_{0}-S_{3}$ were computed in the UV region of all studied complex spectra, with $\lambda_{\text {cal }}$ lower than $350 \mathrm{~nm}$. According to NTO study, $S_{0}-S_{2}$ absorptions correspond to two NTO pairs with different contribution weights. For Pt-1 and Pt-2, the first Hole-Electron transition (majority) 

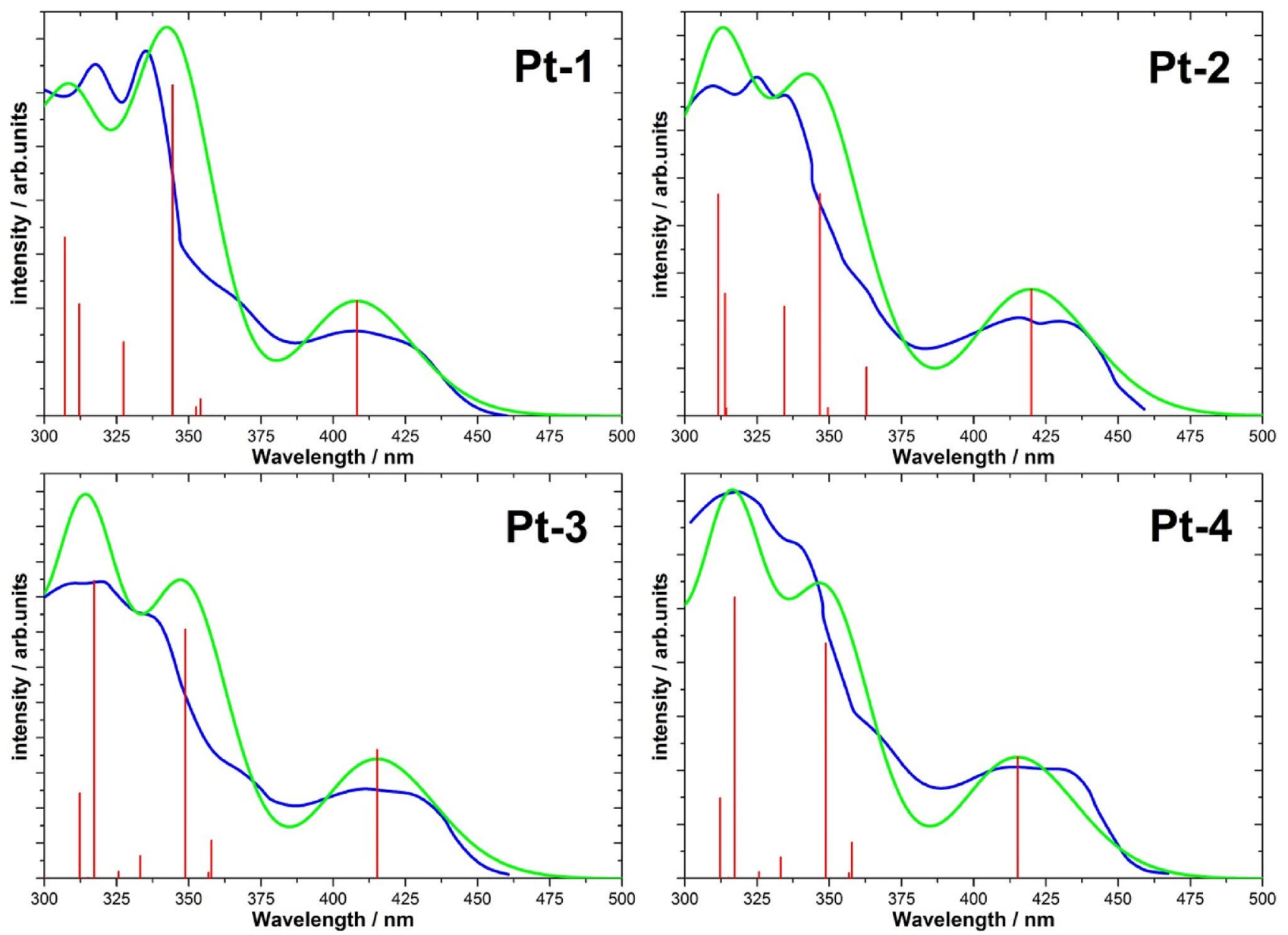

Fig. 2 Simulated (green) and experimental (blue) electronic absorption spectra of studied complexes. Experimental spectra digitized from ref [25]. The calculations were performed in the presence of the solvent chloroform

occurs principally from acetate moiety orbitals to pyridine orbitals, while the second Hole-Electron transition (minority) occurs from $\mathrm{dPt}+\pi_{\text {thiophene }}$ (Hole) to pyridine orbitals (Electron). For Pt-3 and Pt-4, the introduction of quaternary silicon sidechain swap the two NTO pairs, $\mathrm{dPt}+\pi_{\text {thiophene }} \rightarrow \pi_{\text {pyridine }}$ transition (weight $=0.6$ ) become slightly more dominant than $\pi_{\mathrm{acac}} \rightarrow \pi_{\mathrm{py}}$ transition (weight $=0.4$ ). For the second intense absorption $S_{0}-S_{3}$, the two Hole-Electron transitions with large (0.7) and low (0.4) contribution weights have principally a pure LLCT charge transfer character. The large one corresponds to $\pi_{\text {acac }} \rightarrow \pi_{\text {pyridine }}$ transition while the weak corresponds to $\pi_{\text {thpy }} \rightarrow \pi_{\text {acac }}$ transition. The introduction of sidechain ligand to the reference complex Pt-1 causes a bathochromic shift of the electronic absorption spectrum without modifying its shape.

\subsection{First triplet excited state properties}

First triplet excited states $T_{1}$ of studied complexes have been optimized using UB3PW91 methods. A comparison between selected structural parameters of $\mathrm{S}_{0}$ and $\mathrm{T}_{1}$ of Pt-1, Pt-2, Pt-3 and Pt-4 complexes is reported in Table 4 and in Fig. 3. Around the metal, $\mathrm{Pt}-\mathrm{C}_{1}$ bond length between platinum and the thiophene is the most modified bonds between $\mathrm{S}_{0}$ and $\mathrm{T}_{1}$ structures. In $\mathrm{T}_{1}$ thiophene ligand comes closer to the Pt by $0.025 \AA$ (Pt-1), $0.04 \AA$ (Pt-2), $0.028 \AA$ (Pt-3) and $0.029 \AA$ (Pt-4) compared to $\mathrm{S}_{0}$. While $\mathrm{Pt}-\mathrm{O}_{2}$ and $\mathrm{Pt}-\mathrm{N}$ bond lengths change by about $\sim 0.01 \AA$ in all complexes. Same, $\mathrm{S}_{0}-\mathrm{T}_{1}$ transition turn pyridine nitrogen closer to the metal by $\sim 0.01 \AA$. Counter to the bond lengths (Pt-ligand) discussed above, $\mathrm{Pt}-\mathrm{O}_{1}$ bond length between $\mathrm{Pt}$ and acac do not change dramatically after $S_{0}-T_{1}$ transition. After 
Table 3 NTO pairs of selected singlet excited states of Pt-3 and Pt-4 obtained with B3PW91

\begin{tabular}{|c|c|c|c|c|}
\hline \multirow[t]{2}{*}{ Stat } & \multicolumn{2}{|l|}{ Pt-3 } & \multicolumn{2}{|l|}{ Pt-4 } \\
\hline & Hole & Electron & Hole & Electron \\
\hline$S 1$ & 0.9 & & 0.9 & \\
\hline$S 4$ & 0.6 & & 0.6 & \\
\hline & 0.3 & & 0.3 & \\
\hline$S 6$ & 0.6 & & 0.6 & \\
\hline & 0.3 & & 0.2 & \\
\hline
\end{tabular}

relaxation of $\mathrm{T} 1$, intra- and inter-deformation occurs in the ligands. The most affected ligand bond lengths are listed in decreasing order of $\left|T_{1}-S_{0}\right|$ (Table 4). Only ligand bond lengths with $\left|T_{1}-S_{0}\right|>0.001$ are given. As shown in Table 4 (for colored bonds see Fig. 1), the most affected bonds are located in thiophene fragment and in pyridine moiety. This result shows that the electronic redistribution during relaxation process occurs only over thpy ligands. Visualization of unrestricted natural orbitals (NO) shows more clearly the character of all $T_{1}$ (Fig. 4). The singly occupied orbital (SONO) pairs show that electron density distribution is delocalized in thpy ligand orbitals. Both geometry comparison and NO visualization show that $T_{1}$ of the four complexes correspond to ${ }^{3} \mathrm{LLCT}$.

\subsection{Phosphorescence properties}

Luminescence properties of the studied complexes were studied in chloroform solution with the same functional and basic sets used previously. Phosphorescence wavelengths $\left(\lambda_{\max }\right)$ of Pt-1-Pt-4 were computed adiabatically with $\Delta \mathrm{SCF}^{\text {adiab }}$ method (Table 5). According to this procedure, the adiabatic transition energy is obtained as difference between the energies of $T_{1}$ and $S_{0}$ at their optimized geometries. In 
Table 4 Bond lengths (in $\AA$ ) of $S_{0}$ and $T_{1}$ of the studied complexes computed with B3PW91. For bond length colors see Fig. 1

\begin{tabular}{|c|c|c|c|c|c|c|c|c|c|c|c|c|c|c|c|}
\hline \multicolumn{4}{|l|}{ Pt-1 } & \multicolumn{4}{|l|}{ Pt-2 } & \multicolumn{4}{|l|}{ Pt-3 } & \multicolumn{4}{|l|}{ Pt-4 } \\
\hline & $S_{0}$ & $T_{1}$ & $\left|T_{1}-S_{0}\right|$ & & $S_{0}$ & $T_{1}$ & $\left|T_{1}-S_{0}\right|$ & & $S_{0}$ & $T_{1}$ & $\left|T_{1}-S_{0}\right|$ & & $S_{0}$ & $T_{1}$ & $\left|T_{1}-S_{0}\right|$ \\
\hline $\mathrm{Pt} \mathrm{C}_{1}$ & 1.954 & 1.93 & 0.025 & $\mathrm{Pt}-\mathrm{C}_{1}$ & 1.958 & 1.918 & 0.04 & $\mathrm{Pt}-\mathrm{C}_{1}$ & 1.959 & 1.931 & 0.028 & $\mathrm{Pt}-\mathrm{C}_{1}$ & 1.958 & 1.929 & 0.029 \\
\hline $\mathrm{Pt}-\mathrm{O}_{2}$ & 2.008 & 2.025 & 0.017 & $\mathrm{Pt}-\mathrm{O}_{2}$ & 2.104 & 2.088 & 0.016 & $\mathrm{Pt}-\mathrm{O}_{2}$ & 2.102 & 2.112 & 0.01 & $\mathrm{Pt}-\mathrm{O}_{2}$ & 2.011 & 2.022 & 0.011 \\
\hline $\mathrm{Pt}-\mathrm{N}$ & 2.004 & 1.994 & 0.01 & $\mathrm{Pt}-\mathrm{N}$ & 2.007 & 1.991 & 0.016 & $\mathrm{Pt}-\mathrm{N}$ & 2.007 & 1.995 & 0.012 & $\mathrm{Pt}-\mathrm{N}$ & 2.007 & 1.995 & 0.012 \\
\hline $\mathrm{Pt}-\mathrm{O}_{1}$ & 2.102 & 2.103 & 0.001 & $\mathrm{Pt}-\mathrm{O}_{1}$ & 2.012 & 2.018 & 0.006 & $\mathrm{Pt}-\mathrm{O}_{1}$ & 2.011 & 2.021 & 0.01 & $\mathrm{Pt}-\mathrm{O}_{1}$ & 2.108 & 2.111 & 0.003 \\
\hline C- $\mathrm{C}_{\text {black }}$ & 1.395 & 1.483 & 0.088 & C-C $\mathrm{C}_{\text {black }}$ & 1.393 & 1.449 & 0.056 & C- $\mathrm{C}_{\text {black }}$ & 1.395 & 1.482 & 0.087 & C- $\mathrm{C}_{\text {black }}$ & 1.396 & 1.482 & 0.086 \\
\hline $\mathrm{S}-\mathrm{C}_{\text {blue }}$ & 1.737 & 1.793 & 0.056 & C- $\mathrm{C}_{\text {bron }}$ & 1.391 & 1.431 & 0.04 & S- $\mathrm{C}_{\text {blue }}$ & 1.749 & 1.815 & 0.066 & S- $\mathrm{C}_{\text {blue }}$ & 1.748 & 1.815 & 0.067 \\
\hline C-C $\mathrm{C}_{\text {red }}$ & 1.436 & 1.395 & 0.041 & $\mathrm{~S}-\mathrm{C}_{\text {blue }}$ & 1.755 & 1.788 & 0.033 & C- $\mathrm{C}_{\text {red }}$ & 1.44 & 1.396 & 0.044 & $\mathrm{C}-\mathrm{C}_{\mathrm{red}}$ & 1.44 & 1.396 & 0.044 \\
\hline $\mathrm{N}-\mathrm{C}_{\text {green }}$ & 1.375 & 1.412 & 0.037 & $\mathrm{~N}-\mathrm{C}_{\text {grey }}$ & 1.346 & 1.369 & 0.023 & $\mathrm{~N}-\mathrm{C}_{\text {green }}$ & 1.375 & 1.41 & 0.035 & C- $\mathrm{C}_{\text {yellow }}$ & 1.427 & 1.398 & 0.029 \\
\hline C- $\mathrm{C}_{\text {yellow }}$ & 1.429 & 1.403 & 0.026 & $\mathrm{C}-\mathrm{C}_{\mathrm{red}}$ & 1.436 & 1.415 & 0.021 & C- $\mathrm{C}_{\text {yellow }}$ & 1.428 & 1.4 & 0.028 & $\mathrm{C}-\mathrm{C}_{\text {orange }}$ & 1.404 & 1.425 & 0.021 \\
\hline $\mathrm{C}-\mathrm{C}_{\text {mauve }}$ & 1.403 & 1.423 & 0.02 & C- $\mathrm{C}_{\text {yellow }}$ & 1.43 & 1.41 & 0.02 & $\mathrm{C}-\mathrm{C}_{\text {orange }}$ & 1.404 & 1.425 & 0.021 & C- $\mathrm{C}_{\text {mauve }}$ & 1.402 & 1.422 & 0.02 \\
\hline $\mathrm{C}-\mathrm{C}_{\text {orange }}$ & 1.405 & 1.425 & 0.02 & $\mathrm{~N}-\mathrm{C}_{\text {green }}$ & 1.376 & 1.394 & 0.018 & $\mathrm{C}-\mathrm{C}_{\text {mauve }}$ & 1.402 & 1.421 & 0.019 & C- $\mathrm{C}_{\text {pink }}$ & 1.39 & 1.405 & 0.015 \\
\hline C- $\mathrm{C}_{\text {bron }}$ & 1.391 & 1.378 & 0.013 & C-C $\mathrm{C}_{\text {cyan }}$ & 1.391 & 1.408 & 0.017 & C- $\mathrm{C}_{\text {pink }}$ & 1.389 & 1.404 & 0.015 & C- $\mathrm{C}_{\text {bron }}$ & 1.392 & 1.378 & 0.014 \\
\hline C- $\mathrm{C}_{\text {pink }}$ & 1.378 & 1.391 & 0.013 & S- $\mathrm{C}_{\text {olive }}$ & 1.744 & 1.73 & 0.014 & C- $\mathrm{C}_{\text {bron }}$ & 1.392 & 1.378 & 0.014 & $\mathrm{~N}-\mathrm{C}_{\text {grey }}$ & 1.346 & 1.341 & 0.01 \\
\hline
\end{tabular}

Table 5 Computed and experimental phosphorescence wavelengths of the studied complexes calculated with B3PW91

\begin{tabular}{llllll}
\hline & $\Delta$ SCF $^{\text {adiab }}$ & $0-0$ & AS & AH & Exp \\
\hline Pt-1 & 582 & 558 & 684,630 & 560,603 & 560,607 \\
Pt-2 & 607 & 583 & 609,660 & 586,630 & 579.626 \\
Pt-3 & 596 & 572 & 600,649 & 576,620 & 574,622 \\
Pt-4 & 596 & 575 & 602,650 & 580,623 & 577,626 \\
\hline
\end{tabular}

addition, zero-point vibrational energy (ZPVE) corrections have taken in account to get $0-0$ wavelengths. Experimentally the four complexes exhibit two intense bands ( $\alpha$ and $\beta$ ) in the orange region 560-626 nm. Wavelengths computed with $\triangle \mathrm{SCF}^{\text {adiab }}$ are intermediate between the wavelengths of the two intense bands observed in each complex spectrum. ZPVE corrections do not reproduce the experimental values, indeed $0-0$ transition wavelengths are blue shifted compared to $\Delta \mathrm{SCF}^{\text {adiab }}$. One photon phosphorescence spectra of the four complexes were simulated using the Franck-Condon approximation taking in account vibronic contribution to $\mathrm{S}_{0}-\mathrm{T}_{1}$ transition.
Simulated phosphorescence spectra of the studied complexes modelled with $\mathrm{AH}$ and AS are given in Fig. 5 with the digitized experimental spectra. Sufficient spectrum progressions were obtained for all complexes Pt-1 (99\%), Pt2 (98\%), Pt-3 (97\%) and Pt-4 (92\%). As shown in Fig. 5, both $\mathrm{AH}$ and AS phosphorescence spectra are structured and have the same experimental signatures, indeed the two intense bands $\alpha$ and $\beta$ observed in orange region are very well reproduced. Emission energies computed with AS are red shifted compared to $\mathrm{AH}$ and experimental emission energies with deviations from 20 to $30 \mathrm{~nm}$. While the wavelengths of the two intense bands calculated using $\mathrm{AH}$ are very close to the experimental ones with a small average errors less than $6 \mathrm{~nm}$. Phosphorescence bands of Pt-2, Pt-3 and Pt-4 are slightly red shifted compared to Pt-1 which mean that introduction of the sidechain do not affect greatly the emission wavelengths. To accurately determine the emissions colors of studied complexes, color phosphorescence of the four complexes were determined according to Commission Internationale de I'Eclairage 1931 (CIE-1931) color system. CIE $(\mathrm{x}, \mathrm{y})$ coordinates were generated from simulated and experimental spectra using Color-calculator tool
Table 6 Frequencies of selected vibrational modes (in $\mathrm{cm}^{-1}$ )

\begin{tabular}{|c|c|c|c|c|c|c|c|c|c|c|c|}
\hline \multicolumn{3}{|l|}{ Pt-1 } & \multicolumn{3}{|l|}{ Pt-2 } & \multicolumn{3}{|l|}{ Pt-3 } & \multicolumn{3}{|l|}{ Pt-4 } \\
\hline Modes & $\mathrm{S}_{0}$ & $\mathrm{~T}_{1}$ & Modes & $\mathrm{S}_{0}$ & $\mathrm{~T}_{1}$ & Modes & $\mathrm{S}_{0}$ & $\mathrm{~T}_{1}$ & Modes & $\mathrm{S}_{0}$ & $\mathrm{~T}_{1}$ \\
\hline 20 & 425 & 394 & 43 & 616 & 585 & 44 & 620 & 587 & 63 & 618 & 597 \\
\hline 28 & 633 & 585 & 47 & 665 & 645 & 52 & 702 & 698 & 70 & 708 & 699 \\
\hline 34 & 725 & 698 & 51 & 706 & 701 & 86 & 1128 & 1101 & 111 & 1103 & 1099 \\
\hline 54 & 1139 & 1135 & 83 & 1117 & 1109 & 92 & 1222 & 1214 & 121 & 1223 & 1212 \\
\hline 55 & 1172 & 1149 & 92 & 1260 & 1244 & & & & 161 & 1607 & 1557 \\
\hline 58 & 1300 & 1229 & 118 & 1537 & 1523 & & & & & & \\
\hline
\end{tabular}



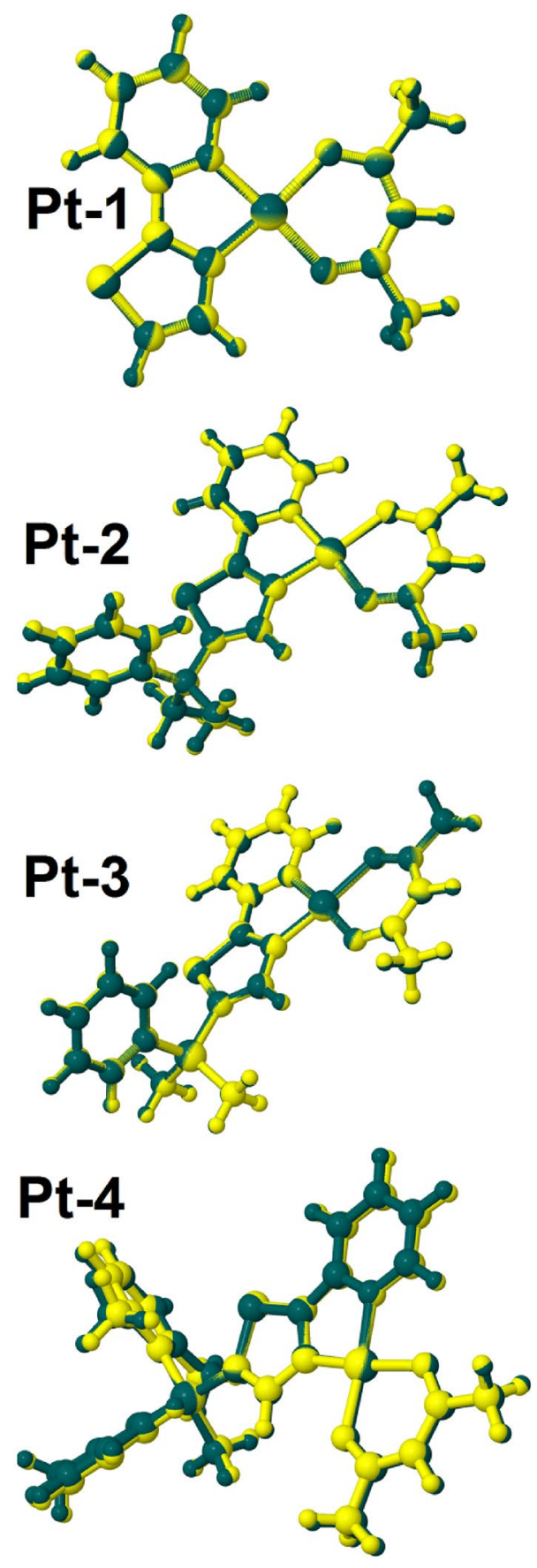

Fig. 3 Superimposed $T_{1}$ and $S_{0}$ geometries of the studied complexes obtained with B3PW91
(Osram Sylvania). As shown in Fig. 6, all CIE coordinates are generated in orange region of horseshoes which meaning that all complexes exhibit orange phosphorescence color and therefore reproduce correctly the experimental colors. However, calculated $(x, y)$ coordinates with $\mathrm{AH} / \mathrm{FC}$ slightly differs from the experimental ones.

The main normal modes involved in the vibronic structure are listed in Table 6 and represented graphically in Table S2. Normal modes were selected according to their contribution intensity in stick spectra (Fig. 5). For all the complexes, the intense bands $(\alpha)$ calculated above $600 \mathrm{~nm}$ with $\mathrm{AH} / \mathrm{FC}$ are contributed by $0-0$ transition. The second intense bands $(\beta)$ computed at less than $600 \mathrm{~nm}$ for all emission spectra are composed of a blend of several vibrational modes. For the complex Pt-1, normal modes $28\left(585 \mathrm{~cm}^{-1}\right), 34\left(698 \mathrm{~cm}^{-1}\right)$, $54\left(1135 \mathrm{~cm}^{-1}\right), 55\left(1149 \mathrm{~cm}^{-1}\right)$ and $58\left(1300 \mathrm{~cm}^{-1}\right)$ have the most intense stick. All these modes correspond to in-plane vibrations localized in thpy ligand. Normal mode 20 and 28 are assigned principally to $\mathrm{C}-\mathrm{H}$ pending and to $\mathrm{C}-\mathrm{C}$ breathing from thiophene and pyridine ligands coupled with $\mathrm{C}-\mathrm{Pt}-\mathrm{N}$ and $\mathrm{C}-\mathrm{S}-\mathrm{C}$ scissoring. The most intense normal mode 34 can be assigned to the breathing of the aromatic pyridine ring and to symmetric stretching of $\mathrm{C}-\mathrm{C}$ and $\mathrm{C}-\mathrm{S}$ bonds in thiophene ring. For Pt-2, the normal modes 43 and 47 computed at 585 and $645 \mathrm{~cm}^{-1}$ correspond to in-plane vibration of the pyridine, to the breathing of phenyl ring and the wagging of methyl groups of the sidechain. Mode 51, represents the most intense vibronic contribution to $\beta$ band. This mode corresponds to o the in-plane bending (scissoring) of pyridine and thiophene fragments. Modes 83 and 92 correspond principally to displacements of the hydrogen atoms of thpy ligand while mode 118 corresponds to $\mathrm{C}-\mathrm{C}$ stretching and $\mathrm{C}-\mathrm{H}$ bending of pyridine group. For Pt-3 the intense band $\beta$ is ascribed to normal modes $44\left(587 \mathrm{~cm}^{-1}\right), 52\left(698 \mathrm{~cm}^{-1}\right), 86\left(1228 \mathrm{~cm}^{-1}\right)$ and 92 $\left(1122 \mathrm{~cm}^{-1}\right)$. Mode 44 which has the most intense stick corresponds to in-plane pending of pyridine and thiophene atoms mixed with wagging of $-\mathrm{CH}_{3}$ fragments. The second intense stick (mode 92) corresponds to in-plane $\mathrm{C}-\mathrm{H}$ scissoring from pyridine and thiophene ligands. For Pt-4, modes 56, 70, 121 and 161 are assigned to the intense band $\beta$. Mode 70 which has the most intense stick corresponds to in-plane scissoring of pyridine and thiophene atoms. While mode 121 corresponds to $\mathrm{C}-\mathrm{H}$ bending of pyridine mixed with $\mathrm{C}-\mathrm{C}$ stretching of 


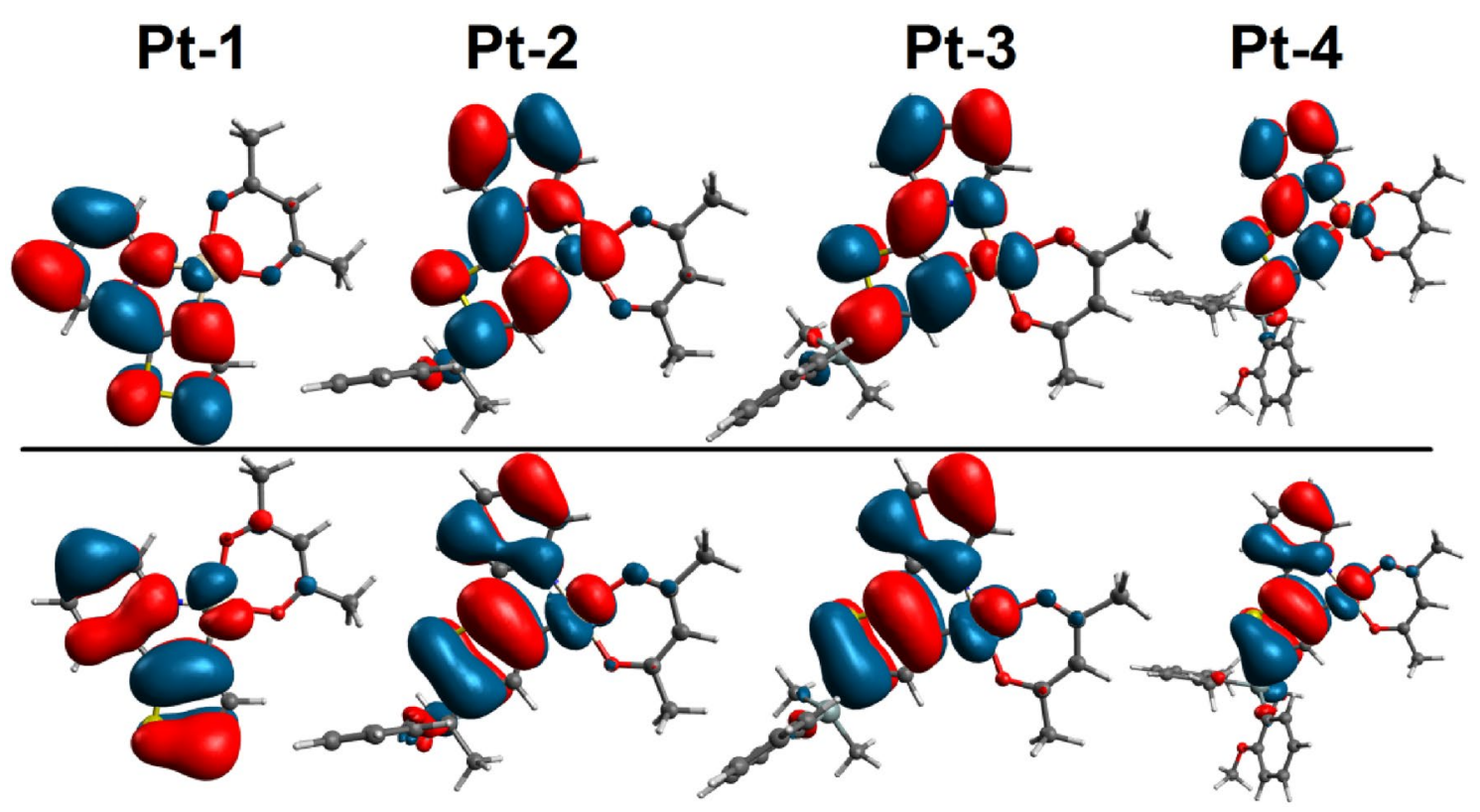

Fig. 4 SONO pairs of the optimized $T_{1}$ obtained with UB3PW91

thiophene. Finally, for the four complexes Pt-1, Pt-2, Pt-3 and Pt-4 the most intense vibronic contributions to $\mathrm{T}_{1}-\mathrm{S}_{0}$ transition are located in pyridine and thiophene fragments. This result is in good agreement with the relaxation process of $T_{1}$ which occurs only over thpy ligand (see Sect. 3.3.).

\section{Conclusion}

In this paper, structural, optical and phosphorescence properties of Pt-1, Pt-2, Pt-3 and Pt-4 were studied using B3PW91 and TD- B3PW91 methods. Calculated geometric parameters reproduced nicely the experimental values. Natural orbital visualizations and geometry comparison $\left(S_{0}-T_{1}\right)$ show that $T_{1}$ of the four complexes correspond to intra-ligand (thpy) charge transfer. Simulated absorption spectra agree with experimental ones in both visible and UV regions. Main absorptions were assigned according to NTO analyzes. FC/AH phosphorescence spectra are structured and have the same experimental signatures. The introduction of the sidechain does not affect greatly the phosphorescence wavelengths. The two intense bands observed in orange region are very well reproduced. Main normal modes contributing to the intense bands were identified. 

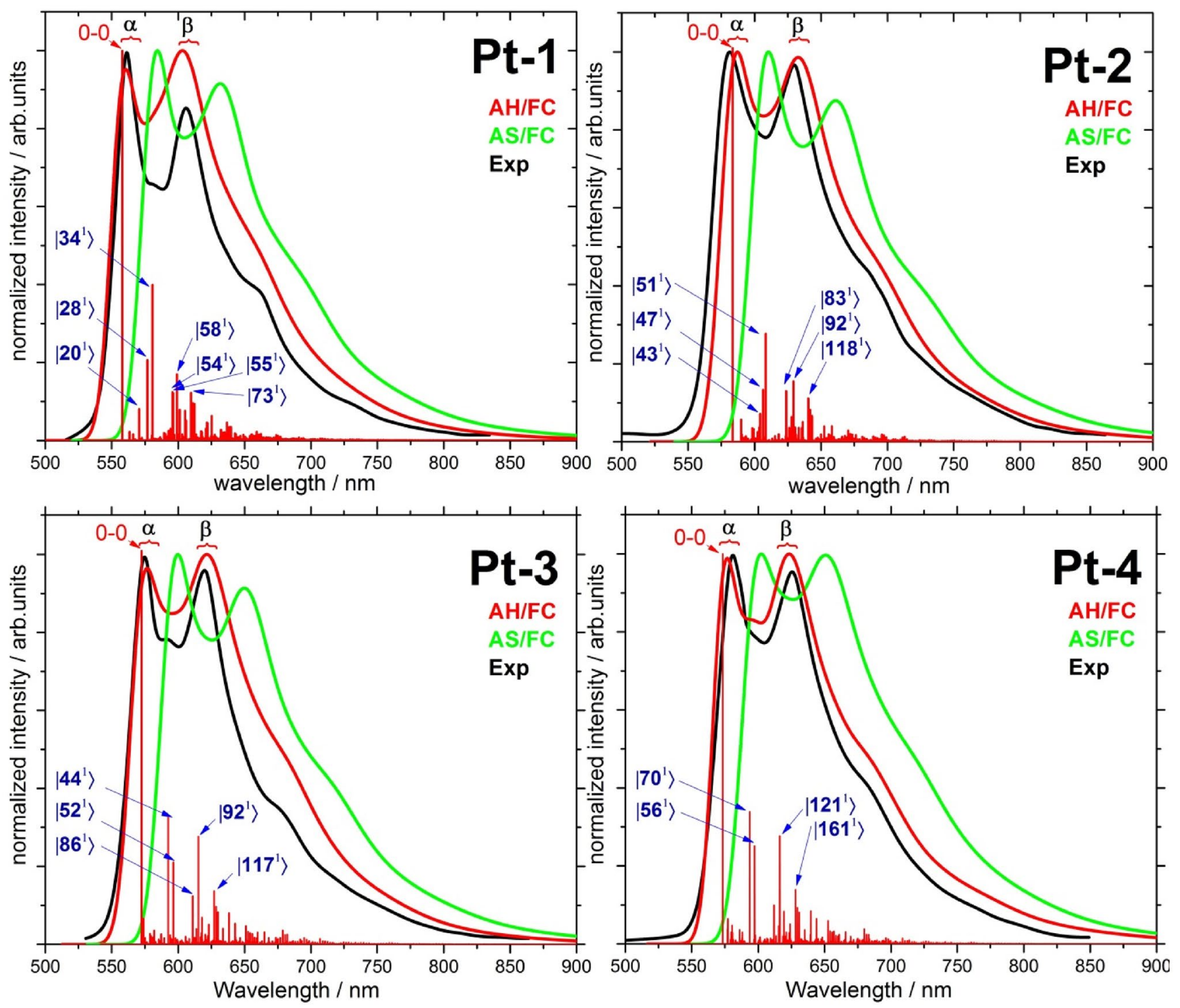

Fig. 5 Simulated and experimental [25] phosphorescence spectra of the studied complexes 

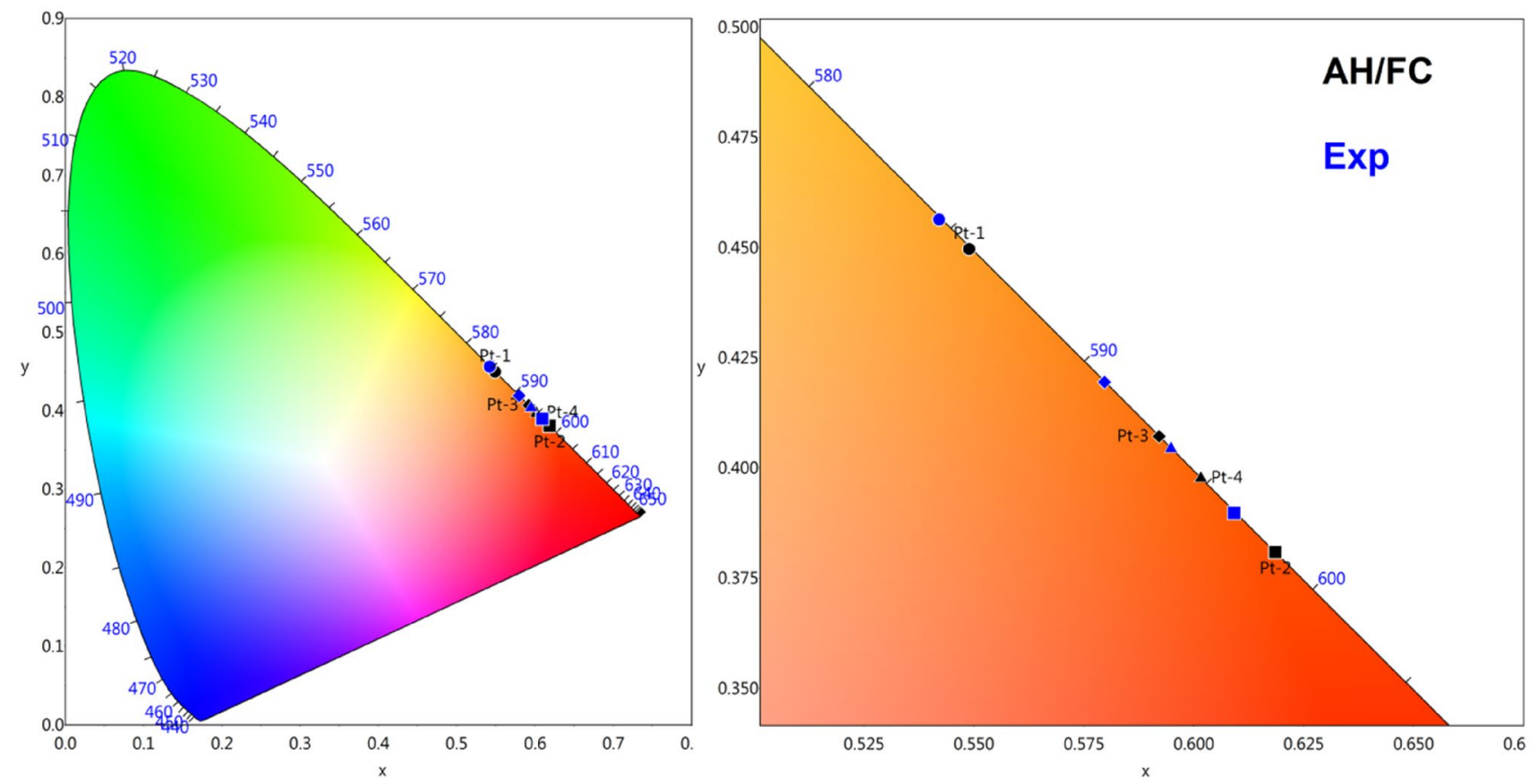

Fig. 6 Horseshoe CIE 1931 color space chromaticity diagrams of studied complexes (left). Zoom of orange region (right)

Supplementary Information The online version contains supplementary material available at https://doi.org/10.1007/s43630-022-00192-5.

Acknowledgements The authors thank the directorate general for scientific research and technological development (DGRSDT), the thematic research agency in science and technology (ATRST) for funding.

Funding This work is part of Projets de Recherche Formation-Universitaire (PRFU, MESRS, Algeria) supported by the directorate general for scientific research and technological development (DGRSDT, www. dgrsdt.dz) and the thematic research agency in science and technology (ATRST, www.atrst.dz). PRFU code: B00L01UN200120190002.

\section{Declarations}

Conflict of interest On behalf of all authors, the corresponding author states that there is no conflict of interest.

\section{References}

1. Barbosa, H. F. G., Attjioui, M., Ferreira, A. P. G., Moerschbacher, B. M., \& Cavalheiro, É. T. G. (2020). New series of metal complexes by amphiphilic biopolymeric Schiff bases from modified chitosans: Preparation, characterization and effect of molecular weight on its biological applications. International Journal of Biological Macromolecules, 145, 417-428. https://doi.org/10.1016/j. ijbiomac.2019.12.153

2. Casado-Sánchez, A., Uygur, M., González-Muñoz, D., AguilarGalindo, F., Nova-Fernández, J. L., Arranz-Plaza, J., Díaz-Tendero, S., Cabrera, S., Mancheño, O. G., \& Alemán, J. (2019). 8-Mercaptoquinoline as a ligand for enhancing the photocatalytic activity of $\mathrm{Pt}(\mathrm{II})$ coordination complexes: reactions and mechanistic insights. The Journal of Organic Chemistry, 84(10), 6437-6447. https://doi.org/10.1021/acs.joc.9b00520

3. Cheng, G., Kwak, Y., To, W.-P., Lam, T.-L., Tong, G. S. M., Sit, M.-K., Gong, S., Choi, B., Choi, W. I., Yang, C., \& Che, C.-M. (2019). High-Efficiency Solution-Processed Organic Light-Emitting Diodes with Tetradentate Platinum(II) Emitters. ACS Applied Materials \& Interfaces, 11(48), 45161-45170. https://doi.org/10. 1021/acsami.9b11715

4. Dragonetti, C., Fagnani, F., Marinotto, D., di Biase, A., Roberto, D., Cocchi, M., Fantacci, S., \& Colombo, A. (2020). First member of an appealing class of cyclometalated 1,3-di-(2-pyridyl)benzene platinum(ii) complexes for solution-processable OLEDs. Journal of Materials Chemistry C, 8(23), 7873-7881. https://doi.org/10. 1039/d0tc01565b

5. El-Sayed, M. Y., Fetooh, H., Refat, M. S., Eldaroti, H. H., Adam, A. M. A., \& Saad, H. A. (2019). Complexes of the plant hormone gibberellic acid with the Pt(II), Au(III), Ru(III), V(III), and Se(IV) ions: Preparation, characterization, and in vitro evaluation of biological activity. Journal of Molecular Liquids, 296, 111895. https://doi.org/10.1016/j.molliq.2019.111895

6. Sobottka, S., Nößler, M., Ostericher, A. L., Hermann, G., Subat, N. Z., Beerhues, J., Behr van der Meer, M., Suntrup, L., Albold, U., Hohloch, S., Tremblay, J. C., \& Sarkar, B. (2020). Tuning $\mathrm{Pt}(\mathrm{II})$-based donor-acceptor systems through ligand design: Effects on frontier orbitals, redox potentials, UV/Vis/NIR absorptions, electrochromism, and photocatalysis. Chemistry (Weinheim an der Bergstrasse, Germany), 26(6), 1314-1327.

7. Wang, S. F., Yuan, Y., Wei, Y. C., Chan, W. H., Fu, L. W., Su, B. K., Chen, I. Y., Chou, K. J., Chen, P. T., Hsu, H. F., Ko, C. L., Hung, W. Y., Lee, C. S., Chou, P. T., \& Chi, Y. (2020). Highly efficient near-infrared electroluminescence up to $800 \mathrm{~nm}$ using platinum(II) phosphors. Advanced Functional Materials, 30(30), 2002173. https://doi.org/10.1002/adfm.202002173

8. Zhang, Z., Tizzard, G. J., Williams, J. A. G., \& Goldup, S. M. (2020). Rotaxane Pt(II)-complexes: mechanical bonding for 
chemically robust luminophores and stimuli responsive behaviour. Chemical Science, 11(7), 1839-1847.

9. Zhang, Z., Zhao, Z., Wu, L., Lu, S., Ling, S., Li, G., Xu, L., Ma, L., Hou, Y., Wang, X., Li, X., He, G., Wang, K., Zou, B., \& Zhang, M. (2020). Emissive platinum(II) cages with reverse fluorescence resonance energy transfer for multiple sensing. The Journal of the American Chemical Society, 142(5), 2592-2600.

10. Brahim, H., Haddad, B., Boukabene, M., Brahim, S., \& Ariche, B. (2017). Theoretical study of geometric structures and electronic absorption spectra of Iridium(III) complexes based on 2-phenyl5-nitropyridyl with different ancillary ligands. Computational and Theoretical Chemistry, 1101, 8-19. https://doi.org/10.1016/j. comptc.2016.12.016

11. Wang, L., Wen, J., He, H., \& Zhang, J. (2014). The reasons for ligand-dependent quantum yields and spectroscopic properties of platinum(ii) complexes based on tetradentate $\mathrm{O}^{\wedge} \mathrm{N}^{\wedge} \mathrm{C}^{\wedge} \mathrm{N}$ ligands: A DFT and TD-DFT study. Dalton Transactions, 43(7), 2849-2858. https://doi.org/10.1039/c3dt52616j

12. Brahim, H. (2019). DFT/TD-DFT investigation on the UV-vis absorption and phosphorescence spectra of platinum(II) and palladium(II) complexes with Schiff-base ligands. Journal of Luminescence, 210, 96-103. https://doi.org/10.1016/j.jlumin. 2019.02.030

13. Guelai, A., Brahim, H., Guendouzi, A., Boumediene, M., \& Brahim, S. (2018). Structure, electronic properties, and NBO and TD-DFT analyses of nickel(II), zinc(II), and palladium(II) complexes based on Schiff-base ligands. Journal of Molecular Modeling. https://doi.org/10.1007/s00894-018-3839-9

14. Schira, R., \& Latouche, C. (2021). DFT vs TDDFT vs TDA to simulate phosphorescence spectra of Pt- and Ir-based complexes. Dalton Transactions, 50(2), 746-753. https://doi.org/10. 1039/d0dt03614e

15. Seghir, I., Nebbache, N., \& Brahim, H. (2021). Geometric, optical, and phosphorescent properties of cationic Ir(III) and Rh(III) complexes with cyclometalated ligands: DFT/TDDFT investigations. Monatshefte für Chemie-Chemical Monthly, 152(3), 315-322. https://doi.org/10.1007/s00706-021-02750-6

16. Luo, Y., Xu, Y., Zhang, W., Li, W., Li, M., He, R., \& Shen, W. (2016). Theoretical insights into the phosphorescence quantum yields of cyclometalated $\left(\mathrm{C} \wedge \mathrm{C}^{*}\right)$ platinum(II) NHC complexes: $\pi$-conjugation controls the radiative and nonradiative decay processes. The Journal of Physical Chemistry C, 120(6), 3462-3471. https://doi.org/10.1021/acs.jpcc.5b12214

17. Stipurin, S., \& Strassner, T. (2021). $C^{\wedge} C^{*}$ platinum(II) complexes with electron-withdrawing groups and beneficial auxiliary ligands: Efficient blue phosphorescent emission. Inorganic Chemistry, 60(15), 11200-11205. https://doi.org/10.1021/acs. inorgchem.1c01172

18. Yang, B., Ni, H., Wang, H., Hu, Y., Luo, K., \& Yu, W. (2020). Enhanced synchronously emission dissymmetry factor and quantum efficiency of circularly polarized phosphorescence from point-chiral cyclometalated platinum(II) liquid crystal. The Journal of Physical Chemistry C, 124(43), 23879-23887. https://doi.org/10.1021/acs.jpcc.0c08106

19. Hadji, D., \& Brahim, H. (2018). Structural, optical and nonlinear optical properties and TD-DFT analysis of heteroleptic biscyclometalated iridium(III) complex containing 2-phenylpyridine and picolinate ligands. Theoretical Chemistry Accounts. https:// doi.org/10.1007/s00214-018-2396-8

20. Matsudaira, K., Mimura, Y., Hotei, J., Yagi, S., Yamashita, K. I., Fujiki, M., \& Imai, Y. (2021). Magnetic circularly polarized luminescence from Pt II OEP and F 2 -ppyPt II (acac) under north-up and south-up Faraday geometries. Chemistry, 16(8), 926-930. https://doi.org/10.1002/asia.202100172
21. Xing, Y., Wang, L., Liu, C., \& Jin, X. (2020). Effects of fluorine and phenyl substituents on oxygen sensitivity and photostability of cyclometalated platinum(II) complexes. Sensors and Actuators B: Chemical, 304, 127378. https://doi.org/10.1016/j.snb.2019. 127378

22. Chen, W. C., Sukpattanacharoen, C., Chan, W. H., Huang, C. C., Hsu, H. F., Shen, D., Hung, W. Y., Kungwan, N., Escudero, D., Lee, C. S., \& Chi, Y. (2020). Modulation of solid-state aggregation of square-planar Pt(II) based emitters: enabling highly efficient deep-red/near infrared electroluminescence. Advanced Functional Materials, 30(25), 2002494. https://doi.org/10.1002/ adfm.202002494

23. Moon, Y. K., Huh, J.-S., Kim, S., Kim, S., Yi, S. Y., Kim, J.-J., \& You, Y. (2020). Synthetic strategy for preserving sky-blue electrophosphorescence in square-planar Pt(II) complexes. ACS Applied Electronic Materials, 2(2), 604-617. https://doi.org/10. 1021/acsaelm.9b00827

24. Zhang, H., Luo, Y., Yan, X., Cai, W., Zhao, A., Meng, Q., \& Shen, W. (2020). Highly efficient blue-emitting of bis-cyclometalated tetravalent platinum (IV) complexes: A theoretical study. Inorganica Chimica Acta, 501, 119269. https://doi.org/10.1016/j.ica. 2019.119269

25. Usuki, T., Uchida, H., Omoto, K., Yamanoi, Y., Yamada, A., Iwamura, M., Nozaki, K., \& Nishihara, H. (2019). Enhancement of the photofunction of phosphorescent $\mathrm{Pt}(\mathrm{II})$ cyclometalated complexes driven by substituents: solid-state luminescence and circularly polarized luminescence. The Journal of Organic Chemistry, 84(17), 10749-10756. https://doi.org/10.1021/acs. joc. $9 \mathrm{~b} 01285$

26. Becke, A. D. (1993). Density-functional thermochemistry. III. The role of exact exchange. The Journal of Chemical Physics, 98(7), 5648. https://doi.org/10.1063/1.464913

27. Boukabene, M., Brahim, H., Hadji, D., \& Guendouzi, A. (2020). Theoretical study of geometric, optical, nonlinear optical, UVVis spectra and phosphorescence properties of iridium(III) complexes based on 5-nitro-2-(2',4'-difluorophenyl)pyridyl. Theoretical Chemistry Accounts. https://doi.org/10.1007/ s00214-020-2560-9

28. Perdew, J. P. (1986). Density-functional approximation for the correlation energy of the inhomogeneous electron gas. Physical Review B, 33(12), 8822-8824. https://doi.org/10.1103/physrevb. 33.8822

29. Perdew, J. P., Burke, K., \& Wang, Y. (1996). Generalized gradient approximation for the exchange-correlation hole of a manyelectron system. Physical Review B, 54(23), 16533-16539. https:// doi.org/10.1103/physrevb.54.16533

30. Hay, P. J., \& Wadt, W. R. (1985). Ab initio effective core potentials for molecular calculations. Potentials for the transition metal atoms Sc to Hg. The Journal of Chemical Physics, 82(1), 270. https://doi.org/10.1063/1.448799

31. Hay, P. J., \& Wadt, W. R. (1985). Ab initio effective core potentials for molecular calculations. Potentials for $\mathrm{K}$ to Au including the outermost core orbitals. The Journal of Chemical Physics, 82(1), 299. https://doi.org/10.1063/1.448975

32. Latouche, C., Palazzetti, F., Skouteris, D., \& Barone, V. (2014). High-accuracy vibrational computations for transition-metal complexes including anharmonic corrections: Ferrocene ruthenocene, and osmocene as test cases. Journal of Chemical Theory Computation, 10(10), 4565-4573. https://doi.org/10.1021/ct5006246

33. Latouche, C., Skouteris, D., Palazzetti, F., \& Barone, V. (2015). TD-DFT Benchmark on inorganic Pt(II) and Ir(III) complexes. Journal of Chemical Theory and Computation, 11(7), 3281-3289. https://doi.org/10.1021/acs.jctc.5b00257 
34. Naoui, M., Brahim, H., \& Guendouzi, A. (2020). Theoretical investigation on green emitting heteroleptic cyclometalated iridium(III) complexes with fluorinated 2-phenylpyridine ligands. Journal of Photochemistry and Photobiology A, 398, 112624. https://doi.org/10.1016/j.jphotochem.2020.112624

35. Cancès, E., Mennucci, B., \& Tomasi, J. (1997). A new integral equation formalism for the polarizable continuum model: Theoretical background and applications to isotropic and anisotropic dielectrics. The Journal of Chemical Physics, 107(8), 3032. https://doi.org/10.1063/1.474659

36. Cossi, M., Barone, V., Mennucci, B., \& Tomasi, J. (1998). Ab initio study of ionic solutions by a polarizable continuum dielectric model. Chemical Physics Letters, 286(3-4), 253-260. https://doi. org/10.1016/s0009-2614(98)00106-7

\section{Authors and Affiliations}

\section{Hadj Mezouar ${ }^{1,2} \cdot$ Houari Brahim ${ }^{1}$}

1 Laboratory of Chemistry Synthesis, Properties and Applications (LCSPA), Faculty of Sciences, University of Saida-Dr Moulay Tahar, Saida, Algeria
37. Allouche, A.-R. (2010). Gabedit-A graphical user interface for computational chemistry softwares. Journal of Computational Chemistry, 32(1), 174-182. https://doi.org/10.1002/jcc.21600

38. Licari, D., Baiardi, A., Biczysko, M., Egidi, F., Latouche, C., \& Barone, V. (2014). Implementation of a graphical user interface for the virtual multifrequency spectrometer: The VMS-Draw tool. Journal of Computational Chemistry, 36(5), 321-334. https://doi. org/10.1002/jcc.23785

39. Frisch, M. J., Schlegel, H. B., Scuseria, G. E., Robb, M. A., Cheeseman, J. R., Scalmani, G., Barone, V., Mennucci, B., Petersson, G. A., Nakatsuji, H., Caricato, M., Li, X., Hratchian, H. P., Izmaylov, A. F., Bloino, J., Zheng, G., Sonnenberg, J. L., Hada, M., Ehara, M., ... Fox, D. J. (2009). Gaussian 09. Gaussian Inc.

2 Laboratoire d'études Physico-Chimiques, University of Saida-Dr Moulay Tahar, Saida, Algeria 